\begin{tabular}{|c|c|c|}
\hline$A$ & $\begin{array}{c}\text { International Journal of Current Research } \\
\text { and Academic Review }\end{array}$ & \\
\hline $\begin{array}{l}\text { EXCELLENT } \\
\text { PUBLISHERS } \\
\end{array}$ & $\begin{array}{c}\text { ISSN: 2347-3215 (Online) } \\
\text { Journal homepage: holume } 5 \text { htp://www.ijcrar.com } \\
\end{array}$ & \\
\hline
\end{tabular}

doi: https://doi.org/10.20546/ijcrar.2017.504.001

\title{
Role of Serum Bilirubin as a Marker for Acute Appendicitis
}

\author{
H.M. Abdulnabi ${ }^{1}$, Waseem Al-katib ${ }^{2}$ and Mais S.M. Shamssa ${ }^{3^{*}}$ \\ ${ }^{1}$ Professor, ${ }^{2}$ Assistant professor, ${ }^{3}$ Lecturer at the Department of General Surgery/Kufa University/Najaf/Iraq and A \\ General Surgeon at Al-Sadr Teaching Hospital/Najaf/Iraq \\ *Corresponding author
}

\begin{abstract}
Acute appendicitis is one of the most common intra-abdominal emergencies seen in the surgical department, which can be treated easily if an accurate diagnosis is made in time; otherwise delay in diagnosis and treatment can lead to gangrene, perforation and diffuse peritonitis. Hyperbilirubinemia is the result of imbalance between production and excretion of bilirubin by the liver and since the liver receive the blood from the portal venous system which carry it from intra-abdominal organ, so any intraabdominal infection including the acute appendicitis could lead to hyperbilirubinemia. In this prospective study, the role of TSB as a marker for acute appendicitis was evaluated.
\end{abstract}

\section{Article Info}

Accepted: 28 March 2017

Available Online: 20 April 2017

\section{Keywords}

Acute appendicitis, total serum bilirubin (TSB), Modified Alvarado Score.

\section{Introduction}

Appendicitis is a surgical emergency, and if it is left untreated, the appendix may rupture and cause a potentially fatal infection (Karamanakos et al., 2010). The causes of appendicitis are not well understood, but it is believed to occur as a result of an obstruction within the appendix. This obstruction would increase intraluminal pressure, which subsequently increases wall tension that leads to ischemia, ulceration, bacterial invasion and ultimately rupture if obstruction is not released (Kim et al., 2010). Although most of the patients with acute appendicitis can be easily diagnosed, in some cases the sign and symptoms are variable and a firm diagnosis is difficult especially if the appendix is retrocaecal or retroileal (Rogozov et al., 2009; Zilbert et al., 2009).

Bilirubin is the end product of the metabolic degeneration of heme. The serum level of bilirubin represents the balance between production and excretion of the breakdown products. Since the bilirubin is a toxic waste product, hepatic handling is designed to eliminate it from the body via the biliary tract through many steps including hepatocellular uptake, intracellular binding, conjugation, including hepatocellular uptake, intracellular binding, conjugation and excretion (William et al., 2001).

Hyperbilirubinemia occurs either due to cholestasis, hepatocellular or hemolytic diseases. Cholestasis and hepatocellular damage are associated with rise in liver enzymes. Cholestasis is failure of normal bile to reach the duodenum; this may be due to pathology anywhere between the hepatocyte and ampulla of Vater. Intrahepatic cholestasis includes that condition where there is no demonstrable obstruction to major bile duct. The causes may be drugs, primary biliary cirrhosis, sepsis or others (Balthazar et al., 1991). Sepsis reaches the liver by various routes, but one of the commonest 
routes is through the portal vein from the gastrointestinal tracts. Any inflammatory condition may cause transmigration /translocation of bacteria, its toxins or cytokines (TNF alpha, IL 6), may cause suppression of the hepatocellular function and reduce the excretion of bile may also alter the hepatic blood flow and normal physiological flow of the bile causing hyperbilirubinemia. It's believed that the obstruction of the lumen (partial /complete) cause accumulation of secretion and distention of lumen, rising the intraluminal pressure. This leads first to lymphatic and later venous obstruction and bacteria overgrowth and oedema, subsequently transmigration of bacteria though the ischemic wall.

Despite the fact that few studies have investigated the role of serum bilirubin in the diagnosis of perforated appendicitis, yet some found that hyperbilirubinemia is an important predictive marker for perforated and necrotizing appendicitis (Oto et al., 2006).

\section{Patients and Methods}

A prospective analytical study of (110) patients who underwent appendectomy, from (11 March 201320 /October 2013) in Al-Sadr Teaching Hospital/Najaf was carried out; Clinic-demographic data Modified Alvarado score, GUE (general urine examination) total serum bilirubin (TSB), total leukocyte count, liver function test and reticular count of all the cases were collected and compared.Initially, 159 patients with modified Alvarado score $\geq 5$ were enrolled in this study; however, forty-nine patients were excluded from the study: three had hemolytic anemia, four had liver disease and the rest had reduced Modified Alvarado score upon subsequent examination(and were discharged from the hospital). The one hundred \& ten patients enrolled in the study had their excised appendix subjected to hisopathological examination. TSB level was considered to be elevated if $\geq 1.4 \mathrm{mg} / \mathrm{dl}$.

Statistical analysis was done using SPSS (Statistic Package for the Social Sciences). The data of all Cases were entered and analyzed; descriptive and analytic statistics were performed using an appropriate statistical configuration.P-value $\leq 0.05$ was considered significant.

\section{Results and Discussion}

Out of 110 patients, $62(56.4 \%)$ were females and 48 $(43.6 \%)$ were males; 50 female patients $(45.4 \%)$ had inflamed appendix on exploration while 41 male patients $(37.3 \%)$ had inflamed appendix Figure. (1)

The Age of the patients ranges from (10-56) years, the commonest age groups were (10-20) years and (20-30) years as in figure (2)

The commonest presenting symptom was abdominal pain (96 patients, 87.2\%) followed by anorexia (86 patients, $78.1 \%$ ), nausea and vomiting (77 patients, 70 $\%)$ as shown in table (2).

The negative appendicectomy rate in female was (19.3 $\%)$ and $(14.5 \%)$ in male.

The highest modified Alvarado score in the enrolled patients was 9 (33 patients, $30 \%$ ), while score was 6 (19 patients, $17.3 \%)$. The positive predictive value of modified Alvarado score is $(82.7 \%)$.

Upon exploration: 19 patients (17.2\%) found to have a normal appendix _ all of them have normal TSB, with no statistically significant difference $(\mathrm{p}$ value $=$ 0.8649 ); while ninety one patients $(82.7 \%)$ had inflamed appendix, from those 25 patients $(22.7 \%)$ had elevated TSB and 66 patients $(60 \%)$ had normal TSB with no statistically significant difference $(p$ value $=0.6884)$.

Of those with inflamed appendix, seventy three patients $(66.3 \%)$ had non-gangrenous appendicitis. Fifteen patients $(13.6 \%)$ of them had elevated TSB and 58 patients $(52.7 \%)$ had normal TSB, with no significant difference $(\mathrm{p}$ value $=0.2432)$. Eighteen patients $(16.3 \%)$ had gangrenous appendicitis on exploration. Ten patient (9\%) of them had elevated TSB while 8 patients $(7.3 \%)$ of them had normal TSB, there is not significant different ( $p$ value $=0.1892)$. See Table. $(4)$

In our study, women have higher negative appendicectomies than men (19.3\% versus $14.5 \%)$, a fact that can be explained by the similarity in presentation of many gynecologic disorders with acute appendicitis. This is comparable to Karamandakos et al., (2010) who reported diagnostic accuracy of acute appendicitis of 78$92 \%$ in males versus $58-85 \%$ in females.

The female to male ratio in our study is 1.2: 1 . This is different from Oto A, Ernst RD, Mileski WJ, Nishino $\mathrm{TK}$, Le $\mathrm{O}$, who reported male preponderance of 3: 2 in teenagers and young adults; in adults, the incidence of appendectomy is approximately 1.4 times greater in men than in women (Oto et al., 2006). This also can be 
explained by some similarity in clinical presentation between acute appendicitis and certain gynecologic disorders.

The commonest age group in our study was those between (10-20 years), while the least was in those > 50 years. This is similar to Schneider et al., (2007) who mentioned that, the incidence of appendicitis gradually rises from birth, peaks in the late teen years, and gradually declines in the geriatric years. Pain was the commonest clinical feature representing $87.2 \%$ of patients, followed by anorexia $(78.1 \%)$, while the lowest was fever $(7.2 \%)$. This low percentage of fever may be due to short time between the start of the inflammation and the medical consultation. This is nearly comparable to Yeh et al., (2008) who reported that the most common symptom of appendicitis is abdominal pain $(80 \%)$. The positive predictive value of modified Alvarado score in our study was $(82.7 \%)$. This is comparable to Shrivastavauk et al., (2007) who demonstrated a positive predictive value of $77.6 \%$ for the Modified Alvarado Score.

Table.1 Presenting symptoms of the studied patients

\begin{tabular}{|l|l|}
\hline Clinical feature & Number of patients (\%) \\
\hline Anorexia & $86(78.1 \%)$ \\
\hline Pain & \\
\hline - Vague abdominal without shift & $40(36.3 \%)$ \\
\hline $\begin{array}{l}\text {-Abdominal pain with shift to right iliac } \\
\text { fossa }\end{array}$ & $56(50.9 \%)$ \\
\hline Nausea/vomiting & $77(70 \%)$ \\
\hline Diarrhea & $13(11.8 \%)$ \\
\hline Constipation & $9(8.1 \%)$ \\
\hline Fever & $8(7.2 \%)$ \\
\hline Dysuria & $23(20.9 \%)$ \\
\hline Menstrual disturbance & $7($ of $62 \mathrm{females})(3.6 \%)$ \\
\hline
\end{tabular}

Table.2 Modified Alvarado score of the studied patients

\begin{tabular}{|c|c|}
\hline Modified Alvarado score & Number of patients(\%) \\
\hline $\mathbf{6}$ & $19(17.3 \%)$ \\
\hline $\mathbf{7}$ & $32(29.1 \%)$ \\
\hline $\mathbf{8}$ & $26(23.6 \%)$ \\
\hline $\mathbf{9}$ & $33(30 \%)$ \\
\hline \multicolumn{2}{|c|}{ Total } \\
\hline \multicolumn{2}{|c|}{ Positive predictive value $\mathbf{= 8 2 . 7 \%}$} \\
\hline
\end{tabular}

Table.3 TSB distribution in the studied patients

\begin{tabular}{|c|c|c|c|c|}
\hline Result of surgery & \multicolumn{2}{|c|}{ TSB } & Total & P value \\
\hline & $+\mathrm{ve}$ & $-\mathrm{ve}$ & & \\
\hline Inflamed appendix & 25 & 66 & 91 & 0.6884 \\
\hline -Non gangrenous & 15 & 58 & 73 & 0.2432 \\
\hline - Gangrenous & 10 & 8 & 18 & 0.1892 \\
\hline $\begin{array}{c}\text { Non-inflamed } \\
\text { appendix }\end{array}$ & 0 & 19 & 19 & 0.8649 \\
\hline Total & 25 & 85 & 110 & \\
\hline Sensitivity = 27.4 \% & & & \\
\hline
\end{tabular}


Fig.1 Appendicular status in the studied group based on gender

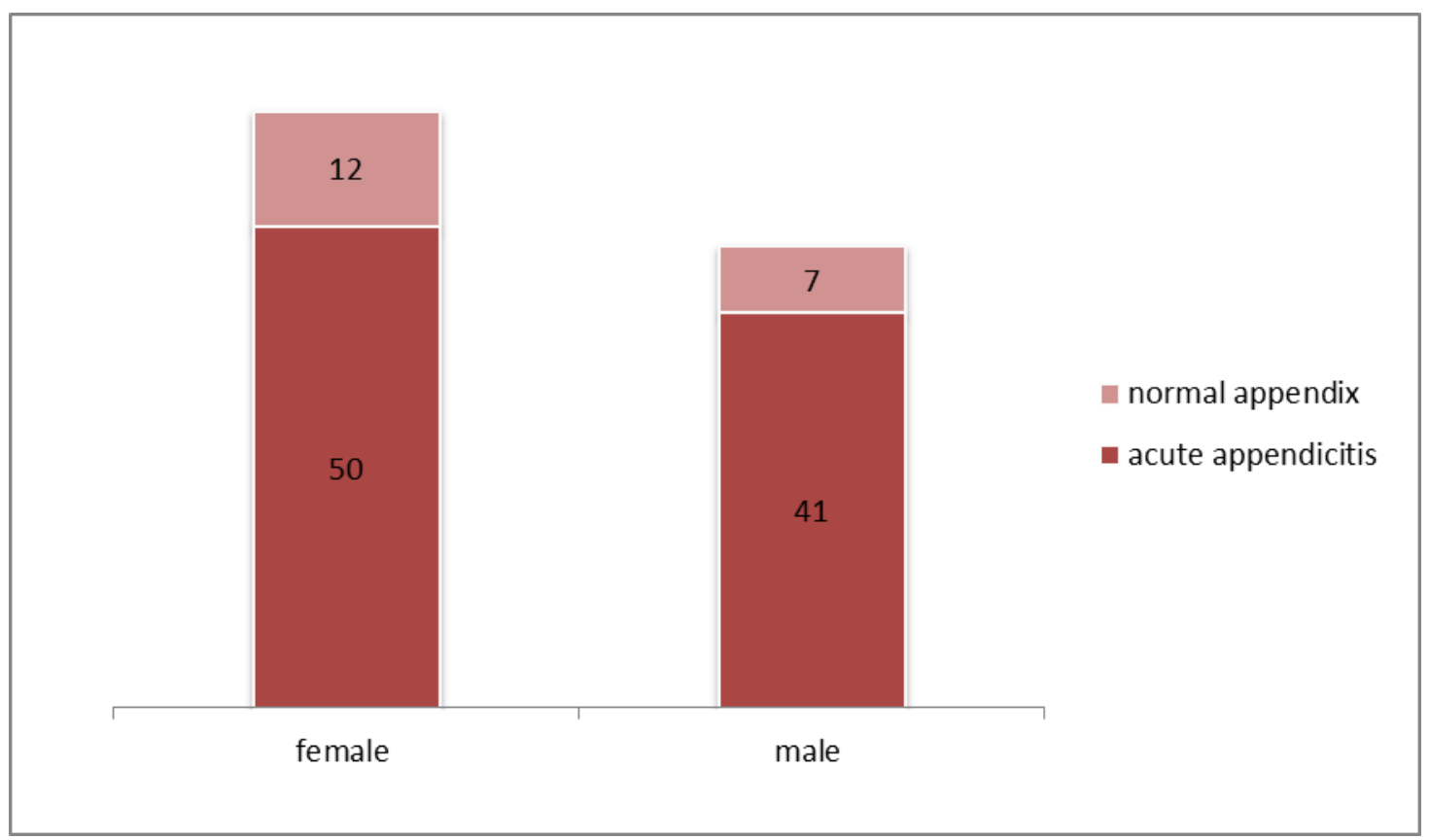

Fig.2 Age groups of the patients enrolled in the study

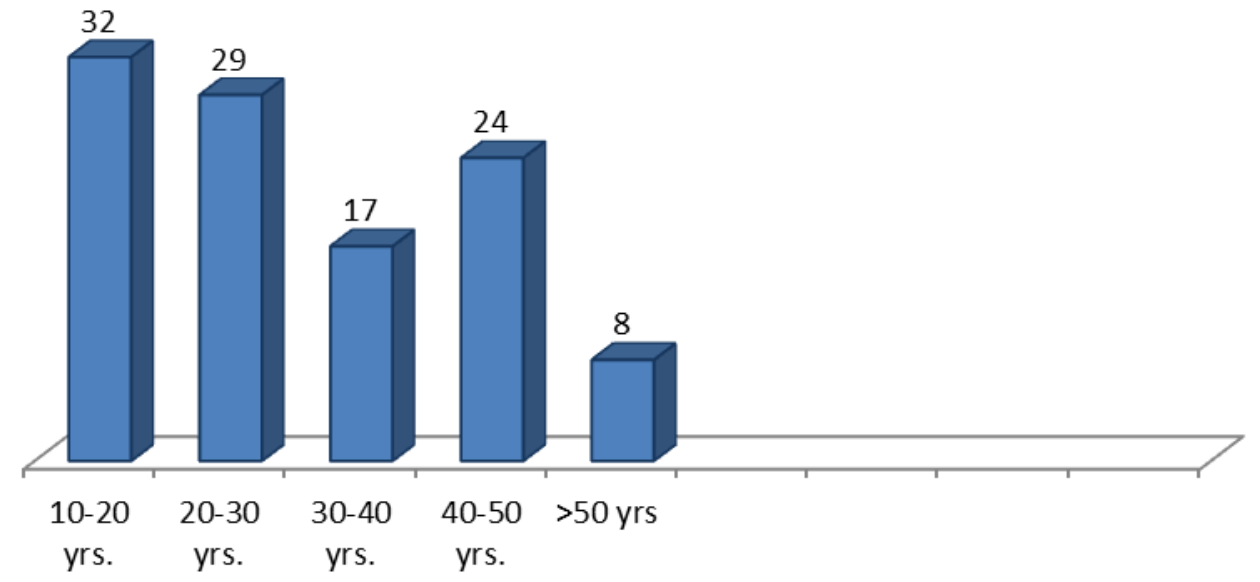

In this study, the sensitivity of TSB in acute appendicitis was $(27.4 \%)$ which is different from Estrada et al., (2007) and Khans et al., (2006) who reported sensitivity $82.07 \%$ and $81.2 \%$ respectively.

In our study, we could not find a statistically significant relation between the TSB level and acute appendicitis (whether gangrenous or not). This in contrast to Ghimire et al., (2012) who found a statistically significant different rise in TSB level in gangrenous appendicitis.

\section{Conclusion}

Pre-operative assessment of total serum bilirubin (TSB) in case of suspected acute appendicitis cannot help as a diagnostic tool for the condition, and does not serve as an important marker of acute gangrenous appendicitis. 


\section{References}

Balthazar, E.J., Megibow, A.J., and Seigel, S.E. 1991. appendicitis: prospective evaluation with high resolution CT, Radiol., 180: 21-4.

Estrada, J.J., Petrosyan, M., Barnhart, J., et al. 2007. hyperbilirubinemia in acute appendesitis, $J$. Gastrointest. Surg., 11(6): 714-8.

Ghimire, P., Thapa, P., Yogi, N. 2012. Role of serumbilirubin as a marker of acute gangrenous appendicitis. Nepal J. Med. Sci., 1(2): 89-92.

Karamanakos, S.N., Serials, E., Panayiotopoulos, S., Kehagias, I. 2010. Laparoscopy in the emergency setting: a retrospective review of 540 patients with acute abdominal pain. Surg. Laparosc. Endosc. Percutan. Tech., 20(2): 119-24.

Khans. 2006. Kathmandu Univ. Med. J. (KUMJ), Evaluations of hyperbilirubinemia in acute inflammation of appendix, (3): 281 -9.

Kim, H.J., Lee, J.I., Lee, Y.S., Lee, I.K., Park, J.H., Lee, S.K., et al. 2010. Single-port transumbilical laparoscopic appendectomy: 43 consecutive cases. Surg. Endosc., 24(11): 2765-9.

Oto, A., Ernst, R.D., Mileski, W.J., Nishino, T.K., Le, O., Wolfe, G.C., et al. 2006. Localization of appendix with MDCT and influence of findings on choice of appendectomy incision. AJR Am. J. Roentgenol., 187(4): 987-90.
Pham, V.A., Pham, H.N., Ho, T.H. 2009. Laparoscopic appendectomy: an efficacious alternative for complicated appendicitis in children. Euro $J$. Pediatr. Surg., 19(3): 157-9.

Rogozov, V., Bermel, N. 2009. "Auto-appendectomy in the Antarctic: case report". BMJ, 339: b49.

Schneider, C., Kharbanda, A., Bacchus, R. 2007. Evaluating appendicitis scoring systems using a prospective pediatric cohort. Ann Emerg. Med., 49(6): 778-84, 784.e1

Shrivastavauk, Gupta, A., Sharma, D. 2004. Evaluation of Alvarado score in the diagnosis of acute appendicitis, Trop. Gastroenterol., 25(4): 184-6.

William, C., Mayers, M.D., Rocco Ricciardi, M.D. 2001.liver function. Sabiston's textbook of surgery. The biological basis of modern surgical practice, $11^{\text {th }}$ edition.

Yeh, B. 2008. Evidence-based emergency medicine/rational clinical examination abstract. Does this adult patient have appendicitis? Ann Emerg. Med., 2(3): 301-3.

Zilbert, N.R., Stamell, E.F., Ezon, I., Schlager, A., Ginsburg, H.B., Nadler, E.P. 2009. Management and outcomes for children with acute appendicitis differ by hospital type: areas for improvement at public hospitals. Clin. Pediatr., (Phila) 48(5): 499504.

How to cite this article:

H.M. Abdulnabi, Waseem Al-katib, Mais S.M. Shamssa. 2017. Role of Serum Bilirubin as a Marker for Acute Appendicitis. Int.J.Curr.Res.Aca.Rev. 5(4), 1-5. doi: https://doi.org/10.20546/ijcrar.2017.504.001 